\title{
Challenges of Global Public Health Emergencies: Development of a Health-Crisis Management Framework
}

\author{
Frederick M. Burkle Jr. ${ }^{1,2}$ \\ ${ }^{1}$ Professor (Ret.), Senior Fellow and Scientist, Harvard Humanitarian Initiative, Harvard University and Harvard \\ T.H. Chan School of Public Health, Cambridge, MA, USA \\ ${ }^{2}$ Senior International Public Policy Scholar, Woodrow Wilson International Center for Scholars, Washington, DC, \\ USA
}

\begin{abstract}
Modern day health care providers have traditionally only focused on meeting the response phase requirements of disasters. The emergence of complex global public health crises such as climate change and extremes, biodiversity loss, emergencies of scarcity, rapid unsustainable urbanization, migrant and refugee surges, domestic and international terrorism, cyber-security, the civilianization of war and conflict, and the global rise of resistant antibiotics has resulted in an unprecedented rise in direct and indirect mortality and morbidity. These crises are beyond the current decision-making and operational capabilities of traditional disaster management and its providers most of who are community level practitioners representing every discipline. The 1930s "disaster cycle" concept describes a phase-related approach to meeting the strategic, operational, research, educational, and training components required of disasters; and, presents an opportunity for the structured development of a Health Crisis Management Framework to oversee the phase-related strategic and operational requirements for prevention, preparedness, response, recovery and rehabilitation challenges of major global public health crises. Whereas this approach mimics the manner in which practitioners at every level of society identify with in their daily practices, this approach deserves the support of every clinician, researcher, academic, and ancillary health care provider. Interestingly, this was also the intent of the original 1930 disaster cycle concept.
\end{abstract}

Keywords: disaster cycle; disasters; global health crises; multidisciplinary framework; public health emergencies Tohoku J. Exp. Med., 2019 September, 249 (1), 33-41. (C) 2019 Tohoku University Medical Press

\section{Introduction}

In 2010, I published on the evolving public health challenges that the medical profession faced with increasingly severe, complex and operationally challenging global humanitarian crises (Burkle 2010). Almost a decade later, we find ourselves redefining the practice, policies, priorities, and research with each catastrophic event. "Public Health," originally defined as the "infrastructure and systems necessary to allow communities, urban settings, and nation-states to provide physical and social protections to their populations", is increasingly under threat by emerging global health crises where it is easily compromised and may functionally disappear. Public health emergencies (PHE), currently defined as "crises that adversely impact the public health system and its protective infrastructure primarily water, sanitation, shelter, food, health and energy," have resulted in unprecedented direct and indirect mortality and morbidity that is increasingly beyond the capabilities of traditional disaster management and its providers.
It is preferential that readers begin to define many of these events discussed here, not as "disasters" per se, but as "crises." Given that "disasters" are historically more often defined as naturally occurring and "sudden-onset" events, the term "disaster" does not incorporate all the catastrophic consequential events that nation-states and the global community face today. With global public health crises rapidly increasing in numbers and severity it is crucial to recognize that:

(1) Many operational competencies, gained through previous disaster education and training, no longer apply,

(2) expertise, once narrowly focused on health outcomes alone, must bring together multidisciplinary and trans-disciplinary skill sets that direct the "integrative expertise" of multiple facets of experts, knowledge, research and epidemiology (MacLachlan 2009), and

(3) the development of decision-making skill sets for global public health crises will benefit from rediscovering strategic, educational and operational pathways first described through the "disaster cycle" framework (Warfield

Received August 19, 2019; revised and accepted August 29, 2019. Published online September 21, 2019; doi: 10.1620/tjem.249.33. Correspondence: Frederick M. Burkle Jr., M.D., M.P.H., D.T.M., Ph.D. (Hon.), F.A.A.P., F.A.C.E.P., Harvard Humanitarian Initiative, 14 Story Street, $2^{\text {nd }}$ Floor, Cambridge, MA 02138, USA. e-mail: fburkle@hsph.harvard.edu; skipmd77@aol.com 
2002), and

(4) current global public health crises and what this means for nation-states within the Asia-Pacific and its increasingly collective global community must be rapidly readdressed at all levels of governance.

Global threats and risks to global public health protections, in particular, have become a "unique phenomenon" in the field of disaster medicine (Al-Jazairi 2017), fostering debate whether the global community of nations needs to recommend "crisis health" as an independent specialty of medicine (Dorling 2018).

\section{The Historic "Disaster" Cycle}

To better understand the evolving roles and responsibilities for healthcare providers, especially those providing policy, practice and leadership guidelines, the original "disaster cycle" concept must be revisited. It provides an authentic societal-level "framework" that is easily understood, conceptually accurate, universally applicable for all providers, and easily applied to all crises no matter how complex (Carr 1932). With increasing complexity of today's crises, the cycle's format provides a structured organizational home to return to, especially when multi-disciplinary decision-making processes are required.

The disaster cycle was first conceived in 1932 when Lowell Carr, a sociologist, first published the sequence pattern of disasters, how they impact society, and how societies traditionally answer to those threats. Carr focused on disaster-related social changes referring to four distinct phases that occurred: "population changes, cultural changes, relational changes, and catastrophic changes." $\mathrm{He}$ then described, also in phases, how societies characteristically answered these challenges, using terms such as: "mitigate, prepare, respond and recover" (Carr 1932).

For many decades public health was viewed as a silent and natural outcome of societal development that guaranteed clean water, food, sanitation, a shelter for the homeless, dealt primarily with the prevention, and openly shunned responsibilities related to crisis events. In the latter part of the $20^{\text {th }}$ century societies actively turned to exploring phases within sudden-onset natural disasters, defined as "large, chaotic, dynamic events in which there is bound to be unpredictability," with the intent that the phases might serve to act as a "road map to make the event and its response "more comprehensible" to those managing the crisis as well as society as a whole (Alexander 2018).

Over decades, the "disaster cycle" incorporated the sequence of phases, as: "prevention, preparedness, response, recovery, and rehabilitation." With the adoption of the cycle phases managers and planners, primarily for natural disaster events, began to select phase-related responsibilities to certain sectors of society. Traditionally, local healthcare providers emerged from where they live and work and focused primarily on the "response phase" alone of the disaster cycle where there is always much to do and learn. Yet in today's more complex crises this is far from adequate. Less than 30 years ago there was never any thought that progress would lead to the development of highly trained pre-hospital emergency personnel, services, and equipment to respond to everyday crises, becoming today a "fixture" in every society (Neal 1997; Luthar 2006). "Disaster professionals," many with research, management, and epidemiological skills, showed that mortality and morbidity were greatly mitigated when professional emergency services are incorporated. Soon recognized as a sub-specialty area, disaster medicine, described its own "disaster cycle" which was the sum of all activities, programs, and measures which are taken up before, during and after a disaster with the purpose to avoid or reduce its impact or recover from its losses (Khan et al. 2017).

Training for crisis events over previous decades resulted in "narrowly focused content specialists" especially on health within the response phase alone (Warfield 2002). All crisis events lead to both direct and indirect (preventable) mortality and morbidity. However, the more the public health infrastructure and its programs are destroyed, the more the direct consequences pale in comparison to the preventable mortality and morbidity numbers. Despite decades where only direct consequences for crises were considered important, all crises today must measure, define and manage both direct and indirect consequences. Only in the last decade have recovery and rehabilitation medicine specialists become an integral part of the phase-related cycle, but have primarily focused on sudden-onset disasters and their consequences (Gosney 2010; Gosney et al. 2011; Reinhardt et al. 2011; Rathore et al. 2012; Khan et al. 2015). While the recent participation in sudden-onset disaster recovery and rehabilitation has been notable, major public health challenges call for a much broader phaserelated integrative approach.

With current crises mounting in severity and length, it has become evident just how limiting it is for practitioners, planners and society alike to exclusively focus on the response phase alone. In part, this is explained by the rapid increase in healthcare practitioner's interest in global health and global public health emergencies. Currently, the younger generation in most countries sees themselves less as nationalists and more as global citizens, actively seeking skill-related educational courses before deployment to humanitarian crises, the content of which primarily arise from operational research related to public health (Burkle et al. 2014).

Unfortunately, for many decades, great ideas for modernizing public health protections failed to be properly legislated. The legal profession dominates the advancement of policies responsible for prioritizing and accelerating legislation through local, state and national governments. Too often, public health advocates lack a presence in the legislative process and in lobbying for the importance of public health agendas as essential priorities. As such, in the US, the capacity to handle crises either stagnated or varied considerably across all 50 states as well as nationally. It would 
take the influenza epidemic in 2009 to first expose these governmental weaknesses. Unfortunately, even today, there is a reluctance of state and local public health departments programs to focus on crisis events, preferring to prioritize on chronic disease prevention. This reality was driven home in 2009 when many state public health departments lacked essential infectious disease epidemiologists which still exists today (Burkle 2011).

The Western world does well with crises we are familiar with. Dilemmas only arise within the response phase when preparation does not meet the realities of the crisis. The "Haitian and Sendai tragedies catalyzed the call to internationally professionalize the major policy and administrative components." This was brought home to Japan when their Disaster Medical Assistance Teams (DMAT) after the Great Tohoku earthquake "found themselves unprepared and overwhelmed, attempting to maintain some semblance of primary healthcare and infrastructure protections (water, sanitation, shelter, food, and basic health) among the half-million evacuated survivors" (Koenig and Burkle 2012). Greater questions and dilemmas followed the Fukushima Dai-ichi Nuclear Power Station tragedy.

The trend today is that public health is rapidly becoming an essential element of all crisis-related disciplines ranging from medicine, engineering, law, social sciences, and economics. History tells us that these warnings to medicine began in 1906 when Osler reminded his medical students at Johns Hopkins that "medicine is the only worldwide profession, following everywhere the same methods, and pursuing the same ends," adding that "this extraordinary solidarity makes the physician at home in any country." While this may not be the case with other disciplines, especially the law and religion, it has resulted in a professional bond that shows this solidarity every day when it comes to global health programs. Readers today accept that Osler's 1906 dialogue and writings that talk of "vaccinations, sanitation, and antisepsis," was referring to the "public health" challenges of the day which slowly revolutionized medicine, unified the medical world, and became a daily expectation of the population (Osler 1906). Public health advances ultimately defined the differences between the "developed and non-developed" countries of the world and identifies those more prone than others to be affected by crisis events. The challenge today requires us to reexplore the increasing dimensions of existing global public health catastrophes that are challenging the global survival for the first time.

A major advance is that many public health practitioners see themselves having responsibilities across the entire "disaster cycle" seeking expertise and applying healthrelated skills to prevention, preparedness, response, recovery, and rehabilitation. In great part, this can be attributed to educational advances and training in countries at great risk, and with the proliferation of major schools of public health, visionary academic programs in developing countries and multiple global online courses. Within Johns
Hopkins University undergraduate school, the most common academic major is "public health" with many students using this as a road to medical and nursing professions, more than half of graduates committed to a career in public health, many further attaining a Master's degree or doctorate in public health. These emerging professionals need to diversify even more, especially in public health policy that moves operational advances into law, currently a recognized and critical weakness (Burkle et al. 2014).

\section{Defining Public Health Crises}

The cross-disciplinary understanding of what and how public health crises translate into operational cooperation before, during, and after an event is paramount. As the same time, various crisis events have begun to be reclassified to meet these demands. Identifying traditional "disaster" classifications first drew from "common agreement" that identified the major categories of natural and humanmade (or technological) disasters (Burkle and Greenough 2008). However, this taxonomy, failing to be sensitive to the increasing range of potential events, prompted Green and McGinnes (2006) to identify the range of events as "natural disasters, human systems failures, and conflictbased disasters." The disaster community of health care providers primarily focused on the response phase of the following events:

- Sudden-Onset Natural Disasters

- Public Health Emergencies of International Concern such as epidemics and pandemics

- War and Conflict.

Making considerable advances in the knowledge base and response capabilities the World Health Organization (WHO) Emergency Medical Teams (EMT) Initiative assists organizations and member states to build capacity and strengthen health systems by coordinating the deployment of quality-assured medical teams in emergencies, primarily naturally occurring disasters and now large infectious disease outbreaks. While it provides a global list of all EMTs that meet the WHO EMT minimum standards for deployment and provides needed time-limited surge clinical capacity to the affected populations, it has little relevance to the additional emerging global crises that directly impact public health, as they are currently conceived, studied and practiced.

In 2008 we described that the "impact of compromised public health infrastructure and systems on health consequences defines and greatly influences how disasters are observed, planned for, and managed, especially those that are geographically widespread, population-dense, and prolonged." We argued that public health and public health infrastructure and systems in developed and developing countries must be seen as "strategic and security" issues that deserve international public health resource monitoring attention from disaster managers, urban planners, the global humanitarian community, WHO authorities, and participating parties to war and conflict. Weary of the magnitude of 
the loss of existing global public health protections which were destroyed and not rebuilt we posited that disaster frameworks be reformed to emphasize and clarify the relation of public health emergencies to the new breed of modern crises (Burkle and Greenough 2008). The list of additional global crises that directly or indirectly target public health infrastructure and protections, as they are currently conceived, studied and practiced include:

- Climate Change/Extremes, Biodiversity Loss, Emergencies of Scarcity and Rapid Unsustainable Urbanization

- Migrant and Refugee Health Crises

- International and Domestic Terrorism

- Chemical and Biological Incidents

- Nuclear Incidents

- Cyber-security

\section{Phase-related Applications to Mitigate Adverse Health Outcomes}

Our roles and responsibilities do not begin and end with the crisis event or the response phase alone. Modernday crisis professionals in health are appreciated for their multiple skillsets applicable across all phases and their abilities to comfortably work as partners within an integrative non-healthcare professional team. This is the most efficient way to discover and apply strategic mitigation tactics within all the phases, the goal being that these factors during a crisis, will come together to limit both direct and indirect mortality and morbidity.

For the listed crisis events, this process calls for the development of Crisis Managers and identification of the specific areas that define priorities for career Health-Crisis Managers. Brief examples are illustrated here emphasizing the plethora of the challenges and the multidisciplinary and trans-disciplinary approaches that are essential to health crisis management, and the directions necessary in education and research inherently evident across all phases. A potential organizational scheme to meet the strategic and operational phase-related health crisis responsibilities is adapted, in part, from The Center for Disaster Philanthropy, and similar to the original "disaster cycle" recommendations of Carr is proposed (Center for Disaster Philanthropy 2019) (Table 1).

The examples, listed below, represent unique challenges that can only be met with phase-related strategic applications across the entire crisis cycle. It assumes that health crisis professionals, in roles of career managers, have the potential to provide a viable model necessary to meet

Table 1. Framework for the proposed Health-Crisis Framework.

\section{PHASE-RELATED HEALTH CRISIS MANAGEMENT:}

(Nation-State Level)

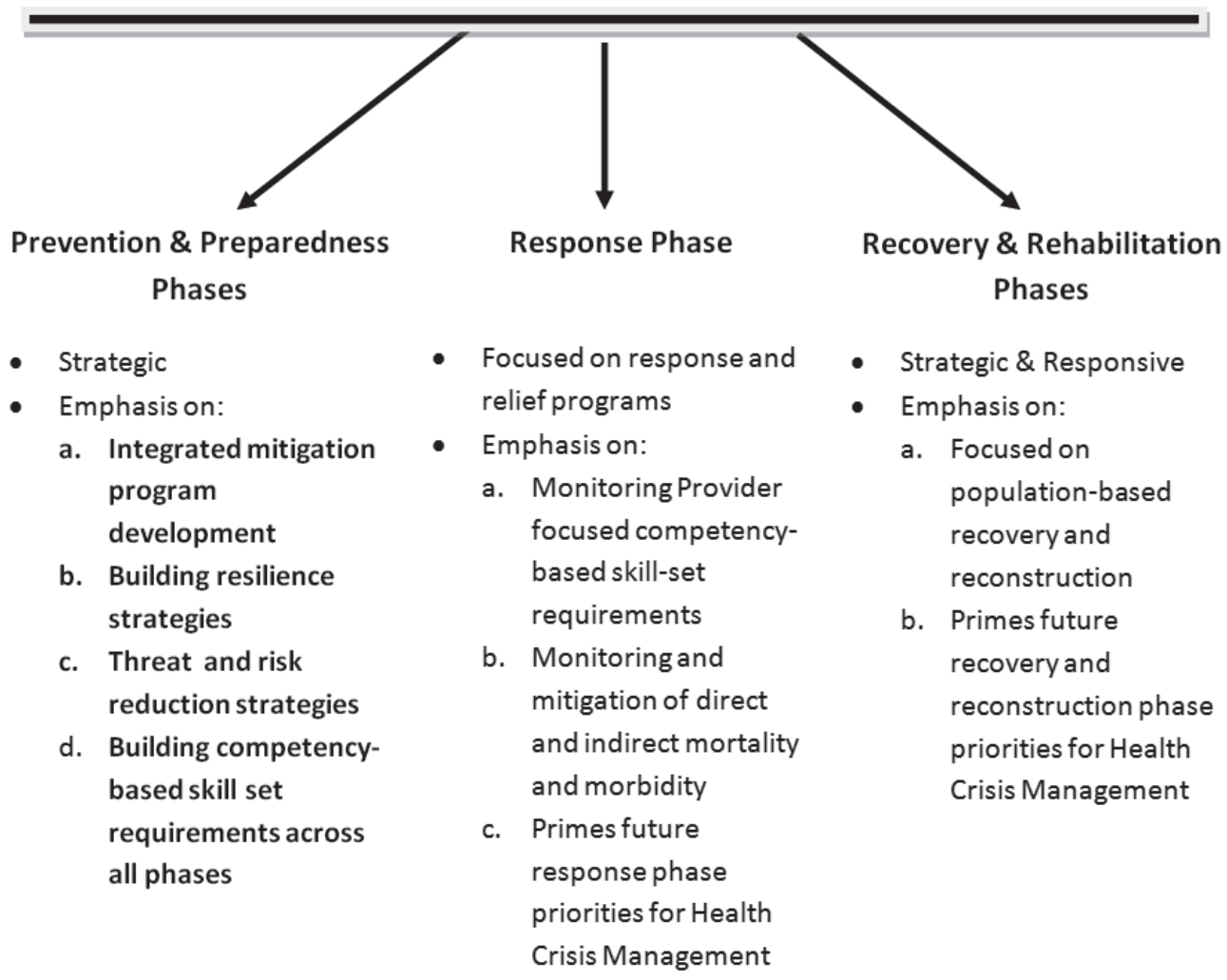

Adapted, in part and with copyright permission, from "The Disaster Life Cycle" Overview, Center for Disaster Philantrophy, Washington DC, 2019. 
the strategic and operational phase requirements of mitigation, response, recovery, and rehabilitation. Focusing alone on the response phase may continue to be a viable approach for WHO-EMT eligible sudden-onset disasters and other time-limited crises.

\section{Climate Change/Extremes}

Current challenges over climate change management provide an excellent example of what issues would face health crisis managers and staff in their daily and strategic duties. Research studies have described a litany of areas where either no consensus has been reached on the validity of the science or outlines the massive responsibility for change that any health crisis manager must face. Concomitantly, climate change and its expressed weather extremes, along with biodiversity losses, and emergencies of scarcity in food, energy and in particular water, remain strategic issues at the level of prevention and preparedness for crisis managers. When unattended, they become the major drivers of crisis-driven public health emergencies and risks for unattended outcomes, including conflict (Burkle 2018) (Fig. 1).

The Balkans, often an area known for outbreaks of territorial, ethnic and religious conflict is currently suffering from climate change-induced severe shortages of water (Cooke 2019). A quarter of the world's population across 17 countries live in "regions of extremely high water stress, a measure of the level of competition over water resources." Qatar, Israel and Lebanon rank at the most water-stressed while revealing a larger more complex and demanding global water crisis that requires "better information, plan-

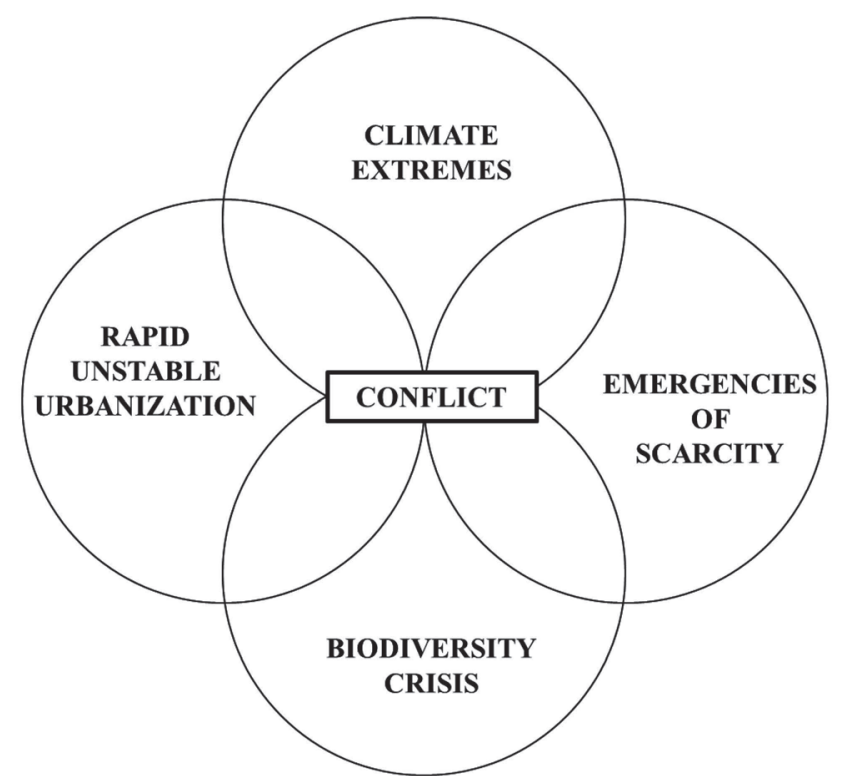

Fig. 1. Venn diagram illustrating the confluence of climate extremes, rapid unsustainable urbanization, emergencies of scarcity and biodiversity crises.

As public health protections disappear, migration may lead to conflict as it has in the Middle East, especially North and Eastern Syria. ning and water management" underscoring the strategic level of concern that these crises provoke (Holden and Doshi 2019). Major threats to include the risk of a "multibreadbasket failure" described as simultaneous crises on several continents and massive migrations triggered by food shortages (Flavelle 2019).

The implementation of flexible adaptation approaches, using frameworks targeted for public health, is key to overcoming the significant barriers to acceptance in public health thinking and the mainstreaming of these approaches into accepted practice. For example, the Building Resilience Against Climate Effects (BRACE) framework which allows health officials to develop strategies and programs to help communities to prepare for the health effects of climate change provides an excellent approach for health adaptation. When combined with adaptation pathways it allows for more deliberate accounting of long-term uncertainties and clear justification for urgent and accelerated efforts to mitigate climate change (Wheeler and Watts 2018). Public health adaptation can operate at two levels, namely, adaptive-capacity building and implementation of adaptation actions. This being said, a high research priority must be given to multidisciplinary research on the assessment of potential health impacts of climate change, projections of health impacts under different climate and socioeconomic scenarios, identification of health co-benefits of mitigation strategies, and evaluation of cost-effective public health adaptation options (Huang et al. 2011).

Austin and colleagues (2016) found that national governments have taken a variety of approaches to public health adaptation that do not follow expected convergence and divergence by governance structure. As such, healthcrisis managers must identify their populations at risk, the health education and public awareness priorities of different groups, broad public health information campaigns, financial support for the position of health-crisis managers and their programs, and assurance that no adaptation strategies will aggravate further health and social inequalities (Holmner et al. 2012). Paavola (2017) identifies social and health inequalities such as age, pre-existing medical conditions, and social deprivations that, along with exposure to heat and cold, air pollution, pollen, food safety risks, disruptions of both access to and functioning of health services and facilities, and both emerging infections and flooding in making people more vulnerable to adverse health outcomes.

Using a structured review method, Curtis and colleagues (2017) suggest that strategic planning, a crucial area of responsibility for any health crisis manager, should be sensitive to country variations, may require changes to already "built infrastructure systems such as transport, utilities and individual care facilities, and to institutional and social infrastructure supporting the health care system." Importantly, they assert that care-sector organizations, communities and individuals alike "need to adapt their practices to improve the resilience of health and health care to extreme weather, and preparedness and emergency response 
strategies that extend beyond the emergency response services, including health and social care providers." Liu and Ma (2019) emphasize that studies of the adverse effects resulting in heat-and cold-related mortality that increase in parallel with climate change must also consider the importance of adaptation in its mitigation schemes.

Crisis managers will find themselves as critical educators in clarifying the scientific data for both the population and political decision-makers, and in developing acceptable "eco-or climate-friendly technologies" as part of their daily health-management toolbox. Health crisis managers must have sensitivity and skills dealing both with the policy restrictions and the expected fracture between the scientific and political world. All health crisis managers need to learn to communicate more effectively to adopt short and longterm solutions through "education" and in accepting the Paris Agreement as an important signal of international consensus just how will these changes benefit society and standard of living (Agre et al. 2017).

Crisis managers will need to evaluate evidence-based research, such as the impacts of climate change on air pollution and air pollution-related health impacts and identify knowledge gaps for future research, and implementation. Current research suggests that outcomes depend highly on the climate change scenario used and on projections of future air pollution emissions, all, unfortunately, elements with relatively high uncertainty. Whereas current studies primarily focused on mortality, projections on the effects on morbidity are also needed (Orru et al. 2017).

More basically, there is an expressed urgency for public health researchers and managers to answer several questions, e.g., how to weigh the health of present and future generations; how to balance between the possible immediate adverse impacts of mitigating climate change versus long-term adverse impacts of global change; how to limit the environmental impacts of public health intervention; and how to allocate resources (Holmner et al. 2012; Storz 2018). Health Crisis Managers would be faced with a moral responsibility to address key elements to ensure longlasting, innovative global change and health solutions summarizing the responsibilities of any future health crisis managers as: (i) empowering the population; (ii) tailoring the framing of global change and health impacts for different stakeholders; (iii) adopting less conservative approaches on reporting future scenarios; (iv) increasing accountability about the health impacts of mitigation and adaptation strategies; and (v) recognizing the limits of science (Pascal et al. 2019).

Existing monitoring and evaluation techniques as practiced in the health sector today do not adequately serve the purposes required by the proposed Health Crisis Manager. Improved indicators are needed in: (1) vulnerability and exposure to climate-related hazards; (2) current impacts and projected risks; and (3) adaptation processes and health system resilience, and an evidence-based approach requiring systematic, coordinated efforts among various stakeholders
(Hess et al. 2014; Ebi et al. 2018). My listing of some of the responsibilities of a proposed health crisis manager is meant to shock the consciousness of current disaster planners, and emphasize why and how climate change poses a wide range of current and future health risks and professional tasks that health professionals need to understand, track, and manage within a broader multidisciplinary framework. Requirements have not and will not be adequately accomplished by existing health professionals relegated to disaster/crisis care.

\section{Cybersecurity}

Kruse and colleagues (2017) identify the healthcare industry as a prime global health target for cybersecurity threats. Breaches include stealing health information and identity theft, ransomware attacks on hospitals, and potentially on implanted medical devises. Increased connectivity to existing computer systems, MRI scanners, blood storage refrigerators, and operating-room equipment have also impacted the ability to care for non-critical emergencies resulting in the diversion of care to other facilities. Besides healthcare, the most vulnerable sectors include energy, transportation, shipping, and telecommunications (Ehrenfeld 2017). Kruse's analysis of 31 articles showed the healthcare industry lags in security. Like other industries, healthcare should clearly define cybersecurity threats and duties, establish clear procedures for upgrading software and handling a data breach, use VLANs to reduce unneeded electronic congestion, de-authentication and cloud-based computing, and to train their users not to open suspicious codes (Kruse et al. 2017). Others stress that "holistic solutions" are required to human behavior, technology and processes with cyber-security becoming an integral part of patient safety and crisis management (Coventry and Branley 2018). These recommendations emphasize unique broadbased solutions that could only be met by phase-based analysis and interventions by trained crisis managers. Success would be measured by cyber-security controlled healthcare mortality and morbidity (Kelpsas and Nelson 2016). Recent reports highlight that health care's "limited resources" and Information Technology (IT) staffing gaps hinder the ability to both understand and transition to more secure platforms. New positions, such as "medical device security engineers" who are a cross between biomedical, IT, and security give credence to the necessity for a new cadre of broadbased emergency specialists that would support the larger health crisis framework emerging from these unique global health threats (Davis 2019).

\section{Chemical and Biological Incidents}

These potential calamities, along with the rise in international and domestic terrorism are also gaining the attention of a phase-related proponent. For example, the recent Ebola crisis in West Africa has stimulated concerns over the protection of medical staff and "how a biological attack from another state or terrorist entity might affect societies 
anywhere." Current legal provisions contain no instructions about how a state party should trigger it if the global community responds after it begins, and the consequential actions it may have on the organization of international assistance beyond that of relief organizations and individual countries (Zanders 2019). Any crisis framework would provide multidisciplinary support including legal and other professional, technical and research entities.

\section{War and Conflict}

Major changes have occurred in how war and conflict occur and practiced (Burkle 2017). Although daily threats of cross-border war from major powers are not uncommon, they have currently been replaced by chronic internal conflicts that catalyze major migrations and refugee flows: Afghanistan conflict, Syrian Civil war, Yemini Crisis, Iraqi insurgency, Boko Haram Insurgency, South Sudan, IsraeliPalestinian conflict, and the Somali and Libyan Civil war just to name a few. The Afghan War, the longest war in U.S. history, overtook the U.S. participation in the Vietnam War in 2010. All wars are public health crises, yet except for counting military casualties, little data exists on the preventable mortality and morbidity of civilians.

All wars, by definition, suffer from ad hoc responses and lack a consistent phase-based understanding, mitigation or organized response recovery, and rehabilitation strategies. Stanford based researchers revealed that in 29 internal conflicts (1990-2017), only 7\% of trauma cases had transport times under 1 hour. Many of the cases were not transported for several hours or days, bringing surgical triage standards and coordination for transportation priority shamelessly close to what was experienced by military casualties in the Napoleonic Wars of the 1800s (Forrester et al. 2019). Also, internal conflicts led to the first incidents of antibiotic resistance to wound infections, a crucial problem now impacting all of global health (Jakovljevic et al. 2018) Establishing civilian standards of care in war and conflict will require unprecedented and currently unavailable phase-related requirements and opportunities provided by international organizations supported by international humanitarian law and the Geneva Convention.

\section{Establishing a Multidisciplinary Framework for Global Health Crises}

My thinking on the critical need for a phase-related framework to deal with multiple health and health-related inputs into decision-making comes primarily from MacLachlan's work emphasizing the importance of "interdisciplinary, inter-ministerial and inter-sectoral working relationships" (MacLachlan 2009) (Table 1). Separately each one is narrowly focused. Practical operationally-based alternative pathways must be created to ensure that the interaction of the different facets of knowledge to reach the requisite "integrative expertise" under the mantle of a Health-Crisis manager is established to create the required broadbased expertise and environment for shared evi- denced-based solutions (MacLachlan 2009). Larken and colleagues (2016) suggests that "large complex partnerships" in research can work well if all parties agree in advance to a "common program," important "core concepts" and the allocation of critical assets are insured. This thinking would be applied to the Health-Crisis support system feeding Crisis managers with information needed to mitigate crisis-related outcomes.

The work of Smith and Weeks also support the effectiveness of multidisciplinary and interdisciplinary integrated team responses to mass casualty crises. What would be required to ensure similar success at the Health Crisis manager level would be "careful planning, protocol and procedure writing, team member selection, training, and practice" among the multidisciplinary team (Adams et al. 2013). Interdisciplinary simply means "combining subjects in a new way, by working between different academic disciplines" further stressing that critical 'real world' problems are more often those that have to do with "health, politics, engineering or cities" (University College of London Arts and Sciences Programmes 2019). Health crises must be managed by a multidisciplinary design. Interdisciplinary collaboration, particularly between natural and social sciences such as global health, is perceived as crucial to solving the significant challenges facing humanity. Despite the need for such collaboration being expressed more frequently, intensely, and considered essential for phaserelated health crisis management it remains unclear to what degree such collaboration actually takes place. The journal Nature's analysis of the extent and impact of research that bridges disciplines assert that global interdisciplinary research is on the rise, and is more applicable to medicine, nursing, and social studies because they incorporate broad fields such as public health and social aspects of medicine. Interestingly, the most interdisciplinary countries that publish more than 30,000 papers per year are India and China, two of the most disaster-prone (Van Noorden 2015). Global health, in general, is "imprecisely defined and still emerging." It emphasizes global health's transnational and cooperative nature compared to other aspects of health as it has become trans-disciplinary and multidisciplinary out of need, uniting several fields such as anthropology, sociology, and fields of practice such as epidemiology, clinical medicine and nursing. This reflects the reality of current field demands and health crisis management requirements (Flood 2017).

\section{Conclusions}

How successful a Health Crisis Framework would be is dependent on the efforts of the global health community and what crisis-prone countries determine is viable. But, drastic measures that include strategic level models must be designed with disaster-savvy health care providers of every discipline and researchers who are key to both its implementation and long term success. The historically-based disaster cycle framework remains a viable model to build 
on. The question is whether the professional global health community is up to the challenge.

\section{Conflict of Interest}

The author declares no conflict of interest.

\section{References}

Agre, P., Molina, M. \& Chu, S. (2017) The real climate debate. Nature, 550, S62-S64.

Adams, L.M., Smith, L. \& Weeks, S. (2013) Multidisciplinary team response to support survivors of mass casualty disasters: a systematic review protocol. JBI Database System. Rev. Implement. Rep., 11, 8-20.

Alexander, D.E. (2018) The Egg Hypothesis.

[Cited: July 4, 2018]

http://emergency-planning.blogspot.com/2018/07/the-egghypothesis.html

[Accessed: July 29, 2019].

Al-Jazairi, A.F. (2017) Disasters and disaster medicine. In Essentials of Accident and Emergency Medicine, edited by Alsheikhly, A.S. IntechOpen, London, UK, pp. 93-118.

Austin, S.E., Biesbroek, R., Berrang-Ford, L., Ford, J.D., Parker, S. \& Fleury, M.D. (2016) Public health adaptation to climate change in OECD countries. Int. J. Environ. Res. Public Health, 13, 889.

Burkle, F.M. Jr. (2010) Future humanitarian crises: challenges for practice, policy, and public health. Prehosp. Disaster Med., 25, 191-199.

Burkle, F.M. Jr. (2011) The limits to our capacity: reflections on resiliency, community engagement, and recovery in $21 \mathrm{st}-$ century crises. Disaster Med. Public Health Prep., 5 Suppl 2, S176-181.

Burkle, F.M. Jr. (2017) The politics of global public health in fragile states and ungoverned territories. PLoS Curr., 9, pii: ecurrents.dis.ba3beede71ca0746a0972aa3837ed618.

Burkle, F.M. Jr. (2018) Current crises \& potential conflicts in Asia and the Pacific: Challenges facing global health or global public health by a different name. Presented at the Institutional Coordination in Disaster Management in the Asia Pacific Conference, 9-10 April 2018, The University of California at Berkeley APEC Study Center \& the University of California San Diego Medical School, USA.

Burkle, F.M. Jr., Egawa, S., MacIntyre, A.G., Otomo, Y., Beadling, C.W. \& Walsh, J.T. (2014) The 2015 Hyogo framework for action: cautious optimism. Disaster Med. Public Health Prep., 8, 191-192.

Burkle, F.M. Jr. \& Greenough, P.G. (2008) Impact of public health emergencies on modern disaster taxonomy, planning, and response. Disaster Med. Public Health Prep., 2, 192-199.

Carr, L.J. (1932) Disaster and the sequence-pattern concept of social change. Am. J. Sociology, 38, 207-218.

Center for Disaster Philanthropy (2019) The Disaster Life Cycle, Overview.

https://disasterphilanthropy.org/issue-insight/the-disaster-lifecycle/

[Accessed: July 14, 2019].

Cooke, K. (2019) Balkan water reserves may soon run short.

[Cited: August 8, 2019]

https://climatenewsnetwork.net/balkan-water-reserves-maysoon-run-short/

[Accessed: August 8, 2019].

Coventry, L. \& Branley, D. (2018) Cybersecurity in healthcare: a narrative review of trends, threats and ways forward. Maturitas, 113, 48-52.

Curtis, S., Fair, A., Wistow, J., Val, D.V. \& Oven, K. (2017) Impact of extreme weather events and climate change for health and social care systems. Environ. Health, 16, 128.
Davis, J. (2019) Has medical device security, awareness improved in healthcare?

[Cited: August 6, 2019]

https://healthitsecurity.com/news/has-medical-device-securityawareness-improved-in-healthcare

[Accessed: August 7, 2019].

Dorling, S. (2018) Short-term effects of natural disasters.

[Cited: October 27, 2018]

https://bizfluent.com/info-8429120-shortterm-effects-naturaldisasters.html

[Accessed: July 4, 2019].

Ebi, K.L., Boyer, C., Bowen, K.J., Frumkin, H. \& Hess, J. (2018) Monitoring and evaluation indicators for climate changerelated health impacts, risks, adaptation, and resilience. Int. $J$. Environ. Res. Public Health, 15, pii: E1943.

Ehrenfeld, J.M. (2017) WannaCry, cybersecurity and health information technology: a time to act. J. Med. Syst., 41, 104.

Flavelle, C. (2019) Climate change threatens the world's food supply, United Nations warns.

[Cited: August 8, 2019]

https://www.nytimes.com/2019/08/08/climate/climate-changefood-supply.html?action $=$ click \& module $=$ Top $\% 20$ Stories \&pgtype $=$ Homepage \&utm_source $=$ Global + Health $+\mathrm{NOW}+\mathrm{M}$ ain + List\&utm campaign $=e 2 c 609 \mathrm{cdb} 0$-EMAIL CAM 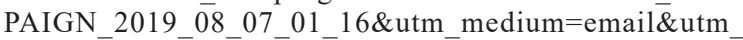 term $=0 \overline{8} \mathrm{~d} 0 \mathrm{~d} 0 \overline{6} 2 \mathrm{~d} \bar{b} \mathrm{~d}-\mathrm{e} 2 \mathrm{c} 609 \mathrm{cdb} 0-86 \overline{3} 223$ [Accessed: August 8, 2019].

Flood, D. (2017) My global health journal list. [Cited: March 6, 2017]

http://www.globalhealthhub.org/2017/03/06/global-healthjournal-list/

[Accessed: August 6, 2019].

Forrester, J.D., August, A., Cai, L.Z., Kushner, A.L. \& Wren, S.M. (2019) The golden hour after injury among civilians caught in conflict zones. Disaster Med. Public Health Prep., 1-9.

Gosney, J., Reinhardt, J.D., Haig, A.J. \& Li, J. (2011) Developing post-disaster physical rehabilitation: role of the World Health Organization Liaison Sub-Committee on Rehabilitation Disaster Relief of the International Society of Physical and Rehabilitation Medicine. J. Rehabil. Med., 43, 965-968.

Gosney, J.E. Jr. (2010) Physical medicine and rehabilitation: critical role in disaster response. Disaster Med. Public Health Prep., 4, 110-112.

Green, W.G. III \& McGinnes, S.R. (2006) Thoughts on the higher order taxonomy of disasters.

[Updated: July 11, 2006]

https://mafiadoc.com/thoughts-on-the-higher-order-taxonomyof-disasters-university-of- $5 \mathrm{a} 258 \mathrm{ff} 81723 \mathrm{dd} 82089 \mathrm{e} 7 \mathrm{fa} 1 . \mathrm{html}$ [Accessed: August 8, 2019].

Hess, J.J., Eidson, M., Tlumak, J.E., Raab, K.K. \& Luber, G. (2014) An evidence-based public health approach to climate change adaptation. Environ. Health Perspect., 122, 11771186.

Holden, E. \& Doshi, V. (2019) Extreme water stress affects a quarter of the world's population, say experts.

[Cited: August 6, 2019]

https://www.theguardian.com/global-development/2019/ aug/06/extreme-water-stress-affects-a-quarter-of-the-worldspopulation-say-experts [Accessed: August 8, 2019].

Holmner, A., Rocklov, J., Ng, N. \& Nilsson, M. (2012) Climate change and eHealth: a promising strategy for health sector mitigation and adaptation. Glob. Health Action, 5, doi: 10.3402/gha.v5i0.18428.

Huang, C., Vaneckova, P., Wang, X., Fitzgerald, G., Guo, Y. \& Tong, S. (2011) Constraints and barriers to public health adaptation to climate change: a review of the literature. Am. J. Prev. Med., 40, 183-190.

Jakovljevic, M., Al Ahdab, S., Jurisevic, M. \& Mouselli, S. (2018) 
Antibiotic resistance in Syria: a local problem turns into a global threat. Front. Public Health, 6, 212.

Kelpsas, B. \& Nelson, A. (2016) Ransomware in hospitals: what providers will inevitably face when attacked. J. Med. Pract. Manage., 32, 67-70.

Khan, F., Amatya, B., Gosney, J., Rathore, F.A. \& Burkle, F.M. Jr. (2015) Medical rehabilitation in natural disasters: a review. Arch. Phys. Med. Rehabil., 96, 1709-1727.

Khan, H., Giurca, L. \& Khan, E. (2017) Disaster management cycle: a theoretical approach.

http://citeseerx.ist.psu.edu/viewdoc/download?doi=10.1.1.551 $.5511 \&$ rep $=$ rep $1 \&$ type $=$ pdf [Accessed: August 16, 2019].

Koenig, K.L. \& Burkle, F.M. Jr. (2012) Downwind from the great tohoku earthquake: a call to global action. West. J. Emerg. Med., 13, 211-212.

Kruse, C.S., Frederick, B., Jacobson, T. \& Monticone, D.K. (2017) Cybersecurity in healthcare: a systematic review of modern threats and trends. Technol. Health Care, 25, 1-10.

Larkan, F., Uduma, O., Lawal, S.A. \& van Bavel, B. (2016) Developing a framework for successful research partnerships in global health. Global Health, 12, 17.

Liu, T. \& Ma, W. (2019) Climate change and health: more research on adaptation is needed. Lancet Planet Health, 3, e281-e282.

Luthar, S.S. (2006) Resilience in development: a synthesis of research across five decades, Chapter 20. In Developmental Psychopathology Vol. 3: Risk, Disorder, and Adaptation, 2nd ed., edited by Cicchetti, D. \& Cohen, D.J. Routledge, London, pp. 739-795.

MacLachlan, M. (2009) Rethinking global health research: towards integrative expertise. Global. Health, 5, 6 .

Neal, D.M. (1997) Reconsidering the phases of disasters. Int. J. Mass Emerg. Disasters, 15, 239-264.

Orru, H., Ebi, K.L. \& Forsberg, B. (2017) The interplay of climate change and air pollution on health. Curr. Environ. Health Rep., 4, 504-513.

Osler, W. (1906) Aequanimitas: with other addresses to medical students, nurses and practitioners of medicine. 3rd ed., The Blakiston Division, McGraw-Hill Book Company, New York, pp. 429-432.

Paavola, J. (2017) Health impacts of climate change and health and social inequalities in the UK. Environ. Health, 16, 113.

Pascal, M., Beaudeau, P., Medina, S. \& Hamilton, N.C. (2019) Global change: a public health researcher's ethical responsibility. Curr. Environ. Health Rep., 6, 160-166.

Rathore, F.A., Gosney, J.E., Reinhardt, J.D., Haig, A.J., Li, J. \& DeLisa, J.A. (2012) Medical rehabilitation after natural disasters: why, when, and how? Arch. Phys. Med. Rehabil., 93, 1875-1881.

Reinhardt, J.D., Li, J., Gosney, J., Rathore, F.A., Haig, A.J., Marx, M. \& DeLisa, J.A.; International Society of Phisical and Rehabilitation Medicine's Sub-Committee on Rehabilitation Disaster Relief (2011) Disability and health-related rehabilitation in international disaster relief. Glob. Health Action, 4, 7191.

Storz, M.A. (2018) A practical guide for physicians and health care workers to reduce their carbon footprint in daily clinical work. Perm. J., 22, 17-145.

University College of London Arts and Sciences Programmes (BASc) (2019) More about interdisciplinarity. https://www.ucl.ac.uk/basc/prospective/faq/interdisciplinarity [Accessed: August 6, 2019].

Van Noorden, R. (2015) Interdisciplinary research by the numbers. Nature, 525, 306-307.

Warfield, C. (2002) The disaster management cycle. http://www.gdrc.org/uem/disasters/1-dm_cycle.html [Accessed: August 16, 2019].

Wheeler, N. \& Watts, N. (2018) Climate change: from science to practice. Curr. Environ. Health Rep., 5, 170-178.

Zanders, J.P. (2019) The trench: recalling where science, industry and the military art converged. Deciding on emergency assistance in case of biological weapons use. http://www.the-trench.org/btwc-article-vii-implementation/ [Accessed: August 8, 2019]. 